\title{
The Research on Online Consumer Finance Innovation Drives by Financial Technology
}

\author{
Chen Yuqing ${ }^{1, a}$ Sun Chenghao ${ }^{2, b, *}$ Sun Yan ${ }^{3, c}$ \\ ${ }^{123}$ Emerging Economic Formats Research Institute of Shandong Management University, \\ Jinan, Shandong province, 250357, China \\ a990802379@qq.com, bsunch2015@163.com, csunyan_2000_715@hotmail.com \\ ${ }^{\star}$ Corresponding author
}

\section{Keywords: financial technology, online consumer finance, innovation model}

\begin{abstract}
This paper summarizes the research status of financial technology, the development of online consumer finance and the innovation model of online consumer finance. It finds that financial technology can promote the efficiency of institutions, promote product innovation and strengthen general benefits and may be legal for consumers. Finally, this paper gives relevant policy recommendations.
\end{abstract}

\section{Background}

In recent years, with the strong support of national policies, the online consumer finance industry has developed rapidly. In 2015 the central bank and the ministry of finance jointly issued the "Guiding Opinions on Promoting the Healthy Development of Internet Finance", which clarified the business boundaries of online consumer finance and the division of responsibilities. The data shows that in 2013 Chinese online consumer finance market transaction volume was about 6 billion yuan, and in 2018 it had exceeded 400 billion yuan. The market size has expanded by nearly 667 times in just five years. Enterprises have intensified their investment in innovation in online consumer finance products. In this process, financial technology played an important role and exposed a series of problems. Therefore, this paper summarizes the research status of financial technology and online consumer finance development, summarizes its innovation model and the effects of financial technology in this process.

\section{Literature review}

\subsection{Financial Technology}

At present, the academic community mainly conducts research on financial technology from the aspects of substance and supervision. In terms of substantive research, Wang (2010) believes that financial technology is essentially financial rather than technology ${ }^{[1]}$. Yi(2017) believes that financial technology is a combination of finance and technology $y^{[2]}$. In terms of regulatory research, $\mathrm{Li}$ (2018) believes that the regulation of financial technology should shift from "command + control" to adaptive regulation ${ }^{[3]}$.

\subsection{Online consumer finance}

Tufano (2009) starts from the functional aspect and believes that consumer finance is a financial function that brings convenience to consumers such as payment, risk management, credit, and savings and investment ${ }^{[4]}$. Wang (2010) regards that individuals and families as the main consumers, and believes that consumer finance is a consumer-related financial activity, including credit, investment, savings, insurance, trust and so on ${ }^{[1]}$. Ye(2015) believes that online consumer finance is a financial activity that provides consumers with services related to consumption through the Internet ${ }^{[5]}$. Huang (2015) believes that online consumer finance is a credit activity that banks, consumer finance companies, and Internet companies use technology tools to lend money to consumers and provide installment payment methods ${ }^{[6]}$. Most of the existing researches mainly 
focus on the development status and innovation trend of online consumer finance in terms of business forms, but few literature combine the development status of financial technology to summarize its innovation model. Therefore, this paper takes the financial technology of each node of the online consumer finance industry chain. Application is the entry point to study the role of financial technology in the development of online consumer finance innovation and summarize it, trying to supplement existing research.

\section{The Innovative Mode of Online Consumer Finance Driven by Financial Technology}

\subsection{Scene construction}

online consumer finance scenes have covered all aspects of consumers' food, clothing, housing and travel. With big data and cloud computing technology, organizations can accurately grasp customers' consumption preferences and provide them with personalized products and services. By analyzing the data, online consumer financial institutions are creating new consumption scenarios based on customer preferences and other information, actively guiding demand direction and focusing on transforming the current situation of user demand-oriented industries.

\subsection{Construction of credit information system}

Construction of credit information system is an important part of development process of online consumer finance. Through big data technology, online consumer financial institutions collect customer information from social platforms, e-commerce platforms and education platforms. Taking Ali-pay's Sesame Credit as an example, it is linked to the customer by means of a quick refund of the e-commerce platform, and the "observance of the contract" data is collected then the sesame score is evaluated regularly. The higher the sesame score, the higher the credit rating of the customer.

\subsection{Innovation in payment methods}

Online payment simplifies payment procedures. Authentication is the core part of the online payment process. Fingerprint is an identity card that does not change, which can provide a valid authentication key for the virtual payment link. Fingerprint identification technology corresponds to the personal information by unique fingerprints. Face recognition is achieved by recording the facial features of the person and verifying the identity. Compared with the fingerprint, face can change with the expression, and lack of uniqueness.

\subsection{Risk management}

Traditional risk management is error-prone and requires a large amount of manpower to analyze the data. Big data technology enables the risk identification mechanism to enter the entire process of online consumer finance business and automatically responds to the potential risks identified by the system and feeds back to the operators, which is a qualitative breakthrough compared to the traditional methods. In addition, online consumer financial institutions can monitor transaction information in real time, and perform targeted operations at the first time of suspicious data to avoid further losses.

\section{The Impact of Financial Technology on Online Consumer Finance}

\subsection{Positive effect}

\subsubsection{Financial technology helps to improve the efficiency of business handling of online consumer} financial institutions

From the perspective of customer credit rating, online consumer financial institutions break through time and space barriers, directly generate customer credit rating reports and determine credit lines. As for product recommendation and configuration, Fin-Tech has realized the personalized development of online consumer financial services through accurate portraits. From the perspective 
of post-loan consultation, the intelligent customer service is always online, and responds quickly according to the keyword questioned by the customer, which largely replaces the labor and improves the efficiency of the post-loan consultation. As for payment collection, the superiority of the intelligent collection system is reflected in the humanized service attitude, avoiding the incident of artificial violence collection and improving the efficiency of collection.

\subsubsection{Financial technology can promote product innovation}

In the absence of technological support, consumer financial product innovation generally requires a lot of manpower. Technology plays an important role in financial innovation and can support it. In the early stage, it can improve the vitality of product innovation. In the medium term, as a necessary tool for the innovation of online consumer finance products, financial technology can facilitate the analysis of product functions, markets and risks by building a big data platform, and improve the efficiency of product innovation. In the later stage, it ensures the safety of new products from the technical level.

\subsubsection{Financial technology helps to enhance the inclusiveness of online consumer finance}

online consumer finance is dedicated to meet the needs of small-sum consumer loans. Financial technology brings consumers with little financial knowledge into the online consumer financial service environment, improves the financial literacy of consumers and builds consumer scenarios through Internet platforms. Furthermore, through the big data and cloud computing, financial technology will flatten and classify customer information, improve the financial institutions' understanding of customer credit, consumption, and demand trends, thereby enhancing the inclusiveness of online consumer financial services.

\subsection{Potential negative impacts}

4.2.1 Financial technology may provide convenience to unscrupulous financial institutions, thereby damaging consumer rights

In the context of the widespread use of big data and cloud computing in the field of online consumer finance, companies have more access to customer information, and their consumption needs and product expectations are accurate. Therefore, products and services may evolve into differentiated pricing based on consumer expectations in the process of personalized development. For example, consumers who are identified as having high price acceptance will face higher prices than others.

4.2.2 Financial technology supervision is difficult, and it is easy to aggravate the chaos of the online consumer finance industry

On the one hand, technological innovation enhances the confidentiality of information in the process of financial services, and on the other hand provides a protection umbrella for scientific and technological violations. online consumer finance has made great progress in the breadth of services, and the integration of different fields also means that cross-latitude business operations become possible. Numerous intermediate links form a sophisticated network. It is difficult to be accurately monitored at which node the funds are transferred and where they go. It can be seen that in the era of financial technology integration into online consumer finance, the phenomenon of crimes using science and technology has begun to appear.

\subsubsection{Financial technology will have an impact on the stability of the financial system}

From a macro perspective, companies are forced to be exposed to market risks. Driven by financial technology, upgrading of online consumer finance products is accelerating. Therefore, the sensitivity of participants to industry information has increased significantly. From a micro perspective, financial technology will have an impact both on consumers and financial institutions. For consumers, malicious theft elements have more means of obtaining consumer information, which may increase the risk of consumer privacy being stolen. For institutions, the technology support of online consumer financial institutions usually comes from independent financial technology companies. If the financial technology company suddenly suffers major changes, Difficulties in operation will lead to disordered technical systems of the online consumer financial institutions and even the collapse of enterprises. 


\section{Conclusions and Policy Recommendations}

By combing the research status of financial technology and online consumer finance and summarizing the innovation model, this paper finds that financial technology plays a facilitating role in the process of institutional innovation, and it also has some negative effects. Based on the prospects for financial technology to drive the development of online consumer finance innovation, the relevant policy recommendations are as follows:

From the perspective of financial technology enterprises, it is necessary to maintain the vitality of scientific and technological innovation, formulate innovative incentive policies within the enterprise, and provide a broad space for development of technology development. It is important to strictly abide by relevant state regulations, actively respond to the guidance on the work of relevant departments, and eliminate the idea of avoiding supervision. In addition, when discovering technical vulnerabilities, it should report to relevant compliance departments and make timely response measures to prevent the expansion of vulnerabilities and affect market stability. From the perspective of online consumer financial institutions, in the process of exploring product and service innovation, on the one hand, it is necessary consciously to obey the industry supervision directives. On the other hand, it is necessary to properly handle the relationship with financial technology enterprises, and to increase the personnel investment in the business connection, finally conduct a comprehensive inspection of the cooperative financial technology enterprises. From the perspective of the regulatory. First, on the basis of encouraging innovation, financial technology enterprises should be classified according to the principles of scale and function, clear business boundaries, and prevent the use of illegal borders. Second, it is necessary to broadly absorb financial science and technology talents, develop unified technical monitoring methods, comprehensively monitor the development status of the underlying technology of financial technology and make possible simulations of its future direction. Third, it is important to enhance the flexibility of regulatory directives. They should train and improve the scientific and technological sensitivities of technicians, and make policy adjustments in a timely manner in response to the changing trend of the financial technology industry.

\section{Acknowledgments}

This research was supported by The School-Level Key Project of Shandong Management University: Research on Credit Risk Evaluation of Small and Medium-sized Enterprises in Shandong Province (XJ20170102)

\section{References}

[1] Wang Jiang, Liao Li, Zhang Jinbao. A Review of Consumer Finance Research[J]. Economic Research, 2010, (s1):5-29.

[2] Yi Xianrong. The Connotation, Essence and Future Development of Financial Science and Technology_ A General Analysis Based on Financial Theory[J]. Jianghai Academic Journal, 2017(2): 13-20.

[3] Li Liao. China Consumer Finance Research Report (2009) [M]. Beijing: Economic Science Press, 2018, 1.

[4] Tufano P. Consumer Finance[J]. Journal of Economic Literature, 2009, 1(1): 227-247.

[5] Ye Xiangrong. Analysis of the New Trend of Consumer Finance Development under the Background of Internet Finance[J].Secretary Letters, 2015(6): 73-77.

[6] Huang Yijun. Research on the Innovation and Development of online consumer Finance[J].Technology Economics and Management Research, 2015(6). 